\title{
Optimization of fish oil extraction from Lophius litulon liver and fatty acid composition analysis
}

\author{
Zhiheng $\mathrm{Hu}^{1,2}$, Yaoxian Chin', Jialin Liu' ${ }^{1,2}$, Jiaying Zhou ${ }^{1,2}$, Gaoshang $\mathrm{Li}^{1,2}$, Lingping $\mathrm{Hu}^{1,2}$, Yaqin $\mathrm{Hu}^{1, *}$ \\ ${ }^{1}$ College of Food Science and Technology, Hainan Tropical Ocean University, Sanya 572022, China \\ ${ }^{2}$ College of Biosystems Engineering and Food Science, National-Local Joint Engineering Laboratory of Intelligent Food Technology and Equipment, \\ Zhejiang Key Laboratory for Agro-Food Processing, Integrated Research Base of Southern Fruit and Vegetable Preservation Technology, Fuli Institute \\ of Food Science, Zhejiang University, Hangzhou 310058, China
}

\begin{abstract}
The Lophius litulon liver was used as raw material for the extraction of fish oil via various extraction methods. The extraction rate by water extraction, potassium hydroxide $(\mathrm{KOH})$ hydrolysis and protease hydrolysis were compared and the results revealed the protease hydrolysis extraction had a higher extraction rate with good protein-lipid separation as observed by optical microscope. Furthermore, subsequent experiments determined neutrase to be the best hydrolytic enzyme in terms of extraction rate and cost. The extraction conditions of neutrase hydrolysis were optimized by single-factor experiment and response surface analysis, and the optimal extraction rate was $58.40 \pm 0.25 \%$ with the following conditions: enzyme concentration 2,000 IU/g, extraction time $1.0 \mathrm{~h}$, liquid-solid ratio $1.95: 1$, extraction temperature $40.5^{\circ} \mathrm{C}$ and $\mathrm{pH} 6.5$. The fatty acids composition in fish oil from optimized extraction condition was composed of $19.75 \%$ saturated fatty acids and $80.25 \%$ unsaturated fatty acids. The content of docosahexaenoic acid (DHA) and eicosapentaenoic acid (EPA) were $8.06 \%$ and $1.19 \%$, respectively, with the ratio (6.77:1) surpassed to the recommendation in current researches (5:1). The results in this study suggest protease treatment is an efficient method for high-quality fish oil extraction from Lophius litulon liver with a satisfactory ratio of DHA and EPA.
\end{abstract}

Keywords: Fish oil, Lophius litulon liver, Protease, Response surface methodology

\section{Introduction}

The rapid development of marine fisheries has brought a vast increase in utilization of marine resources with significant amount of fish by-products. The fish by-products include bone, head, skin and viscera are great sources for proteins, lipids and polysaccharides with biological activities (Alfio et al., 2021).
Fish oil processed from fish by-products is rich in unsaturated fatty acids (UFA), especially of omega-3 (n-3) fatty acids, specifically docosahexaenoic acid (DHA, 22:6) and eicosapentaenoic acid (EPA, 20:5) (Jamshidi et al., 2020). Various researches have revealed the beneficial effects of $\mathrm{n}-3$ fatty acids as a nutrition supplement, and for disease prevention and treatment. Meanwhile, recent studies also indicated that the ratio of DHA and

Received: Oct 7, 2021 Revised: Nov 4, 2021 Accepted: Jan 13, 2022

${ }^{*}$ Corresponding author: Yaqin $\mathrm{Hu}$

College of Food Science and Technology, Hainan Tropical Ocean University, Sanya 572022, China

Tel: +86-15868109010, E-mail: 1004346262@qq.com

This is an Open Access article distributed under the terms of the Creative Commons Attribution Non-Commercial License (http://creativecommons.org/licenses/by$\mathrm{nc} / 4.0 /$ ) which permits unrestricted non-commercial use, distribution, and reproduction in any medium, provided the original work is properly cited.

Copyright $\odot 2022$ The Korean Society of Fisheries and Aquatic Science 
EPA in fish oil is vital to the health of different age groups with the main reason being the particularity of EPA (Kaur et al., 2014; Lunn \& Theobald, 2006). Studies have revealed that the EPA could cause competitive effect with DHA and arachidonic acid (AA) during their metabolism process, resulting in the inhibition in absorption of DHA and AA (Jensen et al., 2000; Sargent et al., 1999). In addition, EPA has a stronger effect in increasing the permeability of heart and blood vessel than DHA, and therefore an intake with larger proportion EPA may cause bleeding in certain vulnerable groups including infants and people with clotting disease (Yang et al., 2020). These properties have caused the content and ratio of $n-3$ fatty acids in fish oil to become a pivotal quality evaluation criterion for fish oil, leading to a demand in source materials with great content and ratio of DHA to EPA.

The Lophius litulon (monkfish) are mainly distributed in the north-east Atlantic and live in a wide bathymetric range from shoal to seafloor of at least 1,000 $\mathrm{m}$ (Laurenson \& Priede, 2005). As an abyssal fish with high nutrition and active substance content, the Lophius litulon have been wildly used for food and nutrition, including as a source bioactive substances and biological material (Lin et al., 2017; Stollewerk et al., 2014; Swart et al., 2019; Vázquez et al., 2020). The fish by-products from Lophius litulon processing could reach about $60 \%$ of the total weight with the liver occupying about $10 \%$. The Lophius litulon liver is always seen as processing waste and is prone to spoilage, but it is rich in nutrients with approximate $30 \%$ of lipids that is high in ratio of polyunsaturated fatty acids (PUFA), making it a potential source for production of high-quality fish oil (Aguilera-Oviedo et al., 2021; Loftsson et al., 2016; Xu et al., 2017).

The traditional method of fish oil extraction is done through pressing and high temperature stewing, which have a low yield and high degradation of active substance (Marsol-Vall et al., 2021). Recent development in fish oil extraction technology has greatly improved the yield, with methods such as solvent extraction, supercritical fluid extraction, pulsed electric field extraction and microwave assisted extraction being increasingly applied commercially (Adeoti \& Hawboldt, 2014; Gulzar et al., 2020). Enzyme extraction is a method with mild reaction condition and high efficiency, whereby the substances bound to the lipid is hydrolyzed. As a result, higher yield of oil is obtained with less pollution and at a lower cost (Maqsood et al., 2012; Sahena et al., 2009). Protease is one of the most important industrial enzymes which could separate protein and lipid from fish tissues by hydrolyzing proteins, obtaining fish oil and some active peptides (Haddar et al., 2010; Rebah \& Miled, 2013). Qi-yuan et al. (2016) used neutral protease to hydrolyze mackerel viscera and confirmed the best reaction conditions using Plackett-Burman design as $1.0 \%$ neutral protease at $\mathrm{pH} 7.3$ and $44.8^{\circ} \mathrm{C}$, that produced $78.66 \%$ fish oil yield which was in agreement with the predicted value. Hathwar et al. (2011) compared four kinds of commercial protease to hydrolyze fish viscera, and concluded that enzyme treatment could improve the extraction rate, with fungal protease reaching the maximum extraction rate in $74.9 \%$, slightly better than other proteases (alcalase, neutrase and protex 7L). Enzyme-assisted aqueous extraction was carried in cobia liver by Wang et al. (2020), in which they found that treatment by papain has a maximum extraction rate of $38 \%$ while obtaining protein hydrolysates with antioxidant activity. These results confirmed the potential application of protease for the extraction of fish oil in Lophius litulon liver.

In this study, the effects of different extraction methods to the extraction of fish oil from Lophius litulon liver were compared. The application of protease in the fish oil extraction has the advantage with higher efficiency than traditional extraction methods, less cost and lower operational complexity than the application of some advanced technology, which provides more potential possibility to the real fish oil industry production. The protease hydrolysis methods were employed by using papain, alcalase, neutrase and flavourzyme, the traditional water extraction and potassium hydroxide $(\mathrm{KOH})$ hydrolysis were compared with protease hydrolysis simultaneously. The extraction process with the application of appropriate protease was further optimized by response surface methodology (RSM) with Box-Behnken design (Zhu et al., 2019). In addition, the protein-lipid distribution in the raw material after different extraction treatments were also observed by optical microscopy and the fatty acid composition in fish oil was analyzed by gas chromatograph-mass spectrometer (GC-MS). We aimed to determine the optimal extraction condition of fish oil from Lophius litulon by protease, which would provide valuable information to the production of high-quality fish oil and added-value to utilization of Lophius litulon liver.

\section{Materials and Methods}

\section{Materials}

Lophius litulon liver were purchased from Bixianyuan Seafood. Papain $\left(8 \times 10^{5} \mathrm{IU} / \mathrm{g}\right.$, EC Number: 3.4.22.2) was purchased 
from Nanjing Dulai Biotechnology (Nanjing, China). Flavourzyme $\left(3 \times 10^{4} \mathrm{IU} / \mathrm{g}\right.$, EC Number: 3.4.15.1) was purchased from Solabio (Beijing, China). Alcalase $\left(2 \times 10^{5} \mathrm{IU} / \mathrm{g}\right.$, EC Number: 3.4.21.62) and neutrase $\left(1 \times 10^{5} \mathrm{IU} / \mathrm{g}\right.$, EC Number: 3.4.24.28) was purchased from Shanghai Yuanye Biotechnology (Shanghai, China). The potassium hydroxide, hydrochloric acid methyl, alcohol and petroleum ether $\left(30^{\circ} \mathrm{C}-60^{\circ} \mathrm{C}\right)$ were analytical grade and purchased from China National Pharmaceutical Group (Beijing, China).The n-hexane was chromatographically pure grade and purchased from Shanghai Macklin Biochemical (Shanghai, China). All other reagents and chemicals used in this study were of analytical grade.

\section{Determination of crude lipid content}

The assay of crude lipid content in liver was carried out by Soxhlet extraction method as described by Luque et al. (2010). The freeze-dried fish liver of $2.0 \mathrm{~g}$ (accurate to $0.001 \mathrm{~g}$ ) was immersed with petroleum ether and refluxed at $60^{\circ} \mathrm{C}$ for $12 \mathrm{~h}$ in a Soxhlet extractor. The solvent was then removed by rotary evaporation and the weight of oil was determined by measuring the weight difference of distilling flask. The content of crude lipid was represented by the quality percentage of extracted lipid to raw material with parallel test in triplicate.

\section{Fish oil extraction and protein-lipid distribution observation} in raw materials

Fish liver of $5.0 \mathrm{~g}$ (accurate to $0.001 \mathrm{~g}$ ) was treated respectively by water extraction, $\mathrm{KOH}$ hydrolysis and protease hydrolysis with reaction conditions as shown in Table 1. The extracted fish oil was separated by high-speed centrifugation. A sample of the reaction solution with $100 \mu \mathrm{L}$ was stained with $1 \%$ bromophenol blue (protein dye) and $0.1 \%$ Sudan IV (lipid dye) to observe the distribution of protein and lipid by optical microscope at $200 \times$ magnification.

Table 1. Extraction condition of different extraction methods

\begin{tabular}{lll}
\hline Extraction method & Extraction temperature $\left({ }^{\circ} \mathrm{C}\right)$ & Extraction $\mathrm{pH}$ \\
\hline Water extraction & 45 & 7.0 \\
KOH hydrolysis & 45 & 6.0 \\
Papain hydrolysis & 60 & 8.0 \\
Alcalase hydrolysis & 40 & 10.0 \\
Neutrasee hydrolysis & 45 & 7.5 \\
Flavourzyme hydrolysis & 53 & 6.5 \\
\hline
\end{tabular}

$\mathrm{KOH}$, potassium hydroxide.
Extraction rate(\%)

$$
=\frac{\text { Fish oil quality from extraction }}{\text { Quality of raw material } \times \text { Crude lipid content }} \times 100 \%
$$

\section{Single-factor experiment of neutrase hydrolysis extraction}

The effects of the single factor change to the fish oil extraction were investigated when the liquid-solid ratio, extraction time, $\mathrm{pH}$ and extraction temperature were chosen as the detected factors. The condition setting was referred by related references and our preliminary experiment (Aitta et al., 2021; Wang et al., 2020).

\section{The influence of liquid-solid ratio}

The liquid-solid ratio was established as the variable factor (1:1, $2: 1,3: 1,4: 1,5: 1)$, and experiments were carried out under the following fixed parameters: enzyme concentration 2,000 IU/g, time $2.0 \mathrm{~h}, \mathrm{pH} 7.5$, and temperature $45^{\circ} \mathrm{C}$. The fish oil extraction rate was taken as evaluation index.

\section{The influence of extraction time}

The extraction time was established as the variable factor $(0.5 \mathrm{~h}$, $1.0 \mathrm{~h}, 1.5 \mathrm{~h}, 2.0 \mathrm{~h}, 2.5 \mathrm{~h}$ ), and experiments were carried out under the following fixed parameters: enzyme concentration 2,000 $\mathrm{IU} / \mathrm{g}$, liquid-solid ratio $2: 1, \mathrm{pH} 7.5$, temperature $45^{\circ} \mathrm{C}$. The fish oil extraction rate was taken as evaluation index.

\section{The influence of $\mathrm{pH}$}

The $\mathrm{pH}$ was established as variable factor $(6.0,6.5,7.0,7.5,8.0)$, and experiments were carried out under the following fixed parameters: enzyme concentration $2,000 \mathrm{IU} / \mathrm{g}$, liquid-solid ratio 2:1, extraction time $1.0 \mathrm{~h}$, temperature $45^{\circ} \mathrm{C}$. The fish oil extraction rate was taken as evaluation index.

\section{The influence of extraction temperature}

The extraction temperature was established as variable factor $\left(35^{\circ} \mathrm{C}, 40^{\circ} \mathrm{C}, 45^{\circ} \mathrm{C}, 50^{\circ} \mathrm{C}, 55^{\circ} \mathrm{C}\right)$, and experiments were carried out under the following fixed parameters: enzyme concentration 2,000 IU/g, liquid-solid ratio 2:1, extraction time $1.0 \mathrm{~h}, \mathrm{pH}$ 6.5. The fish oil extraction rate was taken as evaluation index.

\section{Response surface methodology (RSM) design}

Factors that were significant in the extraction rate in single-factor experiments were further confirmed using RSM and the subsequent value range of factors were approximated. The 
experiment design, model analysis and statistical analysis were carried out by Design-Expert 8.0 using Box-Behnken as the design method. The factor choices and levels were shown in Table 2 and the fish oil extraction rate was served as the response value (Y) (Ying et al., 2021).

\section{Fatty acids composition analysis}

The fatty acids composition in fish oil obtained from optimized conditions was analyzed by GC-MS. A total of $1.0 \mathrm{~g}$ of fish oil (accurate to $0.001 \mathrm{~g}$ ) was added with $10 \mathrm{~mL}$ of $0.5 \mathrm{~mol} /$ $\mathrm{L} \mathrm{KOH}$-methanol solution to perform methyl esterification in $60^{\circ} \mathrm{C}$ water bath for $1.5 \mathrm{~h}$. Upon the completion of reaction, 10 $\mathrm{mL} \mathrm{n}$-hexane was added to extract the fatty acid methyl ester, and the remaining supernatant was washed with distilled water several times with anhydrous sodium sulfate. The mixture was then centrifuged at 5,000 r/min for $10 \mathrm{~min}$, and the supernatant was taken for GC-MS analysis (Zhang et al., 2014). The parameters for GC-MS analysis used were described by Dragalin et al. with slight modifications (Dragalin et al., 2015). Helium was used as the carrier gas with flow rate $1 \mathrm{~mL} / \mathrm{min}$, split ratio $1: 10$, and feed volume 1.0 $\mu \mathrm{L}$. For heating procedure, the temperature was kept at $50^{\circ} \mathrm{C}$ for $2 \mathrm{~min}$, followed by subsequent increment of $15^{\circ} \mathrm{C} / \mathrm{min}$ to $150^{\circ} \mathrm{C}$ (kept for $1 \mathrm{~min}$ ), $10^{\circ} \mathrm{C} / \mathrm{min}$ to $200^{\circ} \mathrm{C}$ ( 2 mins), $3^{\circ} \mathrm{C} / \mathrm{min}$ to $250^{\circ} \mathrm{C}$ (5 mins), and finally $2^{\circ} \mathrm{C} / \mathrm{min}$ to $270^{\circ} \mathrm{C}$ (5 mins). The ionization energy was $70 \mathrm{eV}$, the ion source temperature was $250^{\circ} \mathrm{C}$, the transmission line temperature was $270^{\circ} \mathrm{C}$, and the solvent delay was $3 \mathrm{~min}$. The scanning mode used was full ion scan.

\section{Statistical analysis}

All measurements were done in triplicate. Results were analyzed by IBM SPSS Statistics 25 , and were expressed as mean \pm SD. Significance of results were analyzed using one-way ANOVA and Duncan test at $p \leq 0.05$. All figures and tables were drawn by Origin pro 2017. The response surface experiment was designed by Design Expert 8.0.

\section{Table 2. RSM experimental factors and levels}

\begin{tabular}{lllll}
\hline \multirow{2}{*}{ Factors } & \multicolumn{3}{l}{ Levels } \\
\cline { 3 - 5 } & -1 & 0 & 1 \\
\hline $\mathrm{A}$ & Liquid-solid ratio & $1.5: 1$ & $2.0: 1$ & $2.5: 1$ \\
$\mathrm{~B}$ & Extraction temperature $\left({ }^{\circ} \mathrm{C}\right)$ & 35 & 40 & 45 \\
$\mathrm{C}$ & $\mathrm{pH}$ & 6.0 & 6.5 & 7.0 \\
\hline
\end{tabular}

RSM, response surface methodology.

\section{Results and Discussion}

\section{Protease hydrolysis as a superior extraction method}

The crude lipid content in Lophius litulon liver by Soxhlet extraction was about $33.4 \pm 0.63 \%(n=3)$. The extraction rate by different methods were shown in Fig. 1. In general, the extraction rate of protease hydrolysis was higher than the rate of water extraction and $\mathrm{KOH}$ hydrolysis. Papain had a highest extraction rate at $51.03 \pm 1.93 \%$, while the extraction rate of alcalase and neutrase were similar and had no significant difference between them. However, the extraction rate of alcalase was lowest at $34.28 \pm 0.78 \%$, which may be due to the alkaline reaction condition. The difference of extraction rate between the proteases could also be explained by the difference in hydrolysis degree (DH). In theory, a higher value of $\mathrm{DH}$ would extract more lipid from raw materials, but it could also produce more emulsion containing protein hydrolysate, which negatively affected the lipid extraction rate. Hence, the extraction rate of fish oil was closely related to the properties of the substrate and the type of protease used (Zhu et al., 2010). Considering the extraction efficiency and cost, neutrase was chosen as the hydrolytic enzyme in subsequent experiment.

\section{Distribution of protein and lipid in raw materials by prote- ase extraction}

The distribution situation of protein and lipid in raw materials by different extraction methods were observed using optical microscope. The micrograph of raw materials under different treatments were shown in Fig. 2. The control sample shown in Fig. 2a revealed the initial distribution of protein and lipid, with the lipid molecules (in red) were adsorbed or encased in large protein molecules (dark green), causing a binding effect on the lipids. This bonding between protein and lipid are common in meat and chyle products due to the emulsification of protein. The protein could reduce surface tension by forming a thin film at the oil/water interface and form a stable oil-water mixture to encase the lipid (Han et al., 2021). Shao et al. (2015) studied the interaction between protein and lipid in meat by Raman spectroscopic, and found that the interaction between protein and lipid are mainly disulphide bonds, hydrophobic interactions and hydrogen bonding, which would explain the existence of protein that could inhibit the separation of lipid. After water extraction, it could be observed from Fig. $2 \mathrm{~b}$ that under the polarity effect of water molecules, some oil molecules separated from protein molecules and were free in the solution, but the binding 


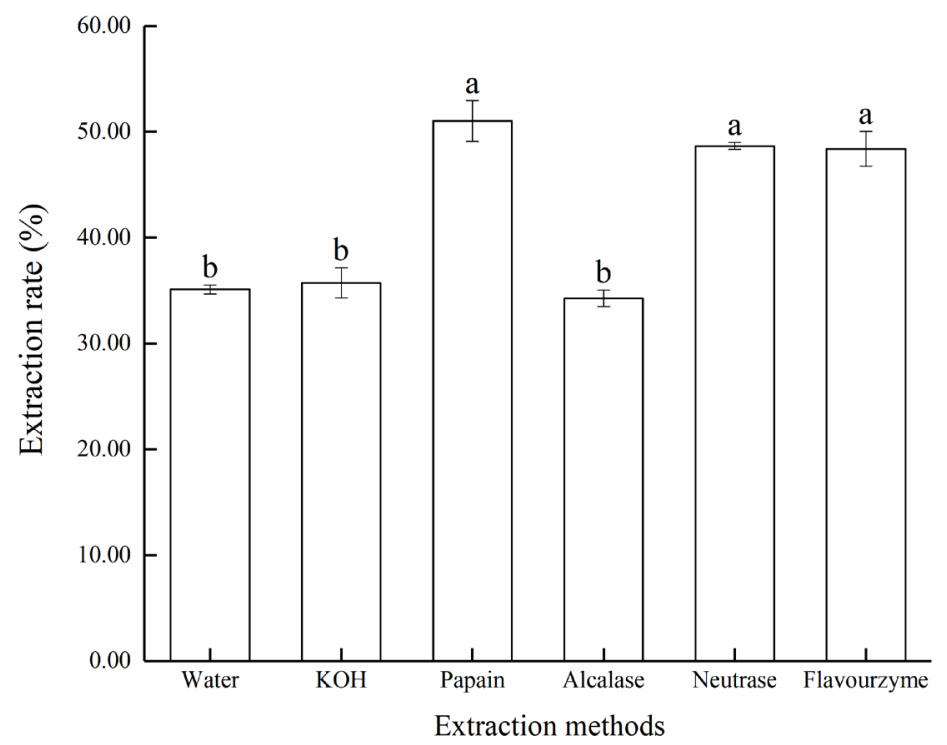

Fig. 1. Effects of different extraction methods on the extraction rate of fish oil. Means with different superscript represents significantly differ $(p<0.05)$.
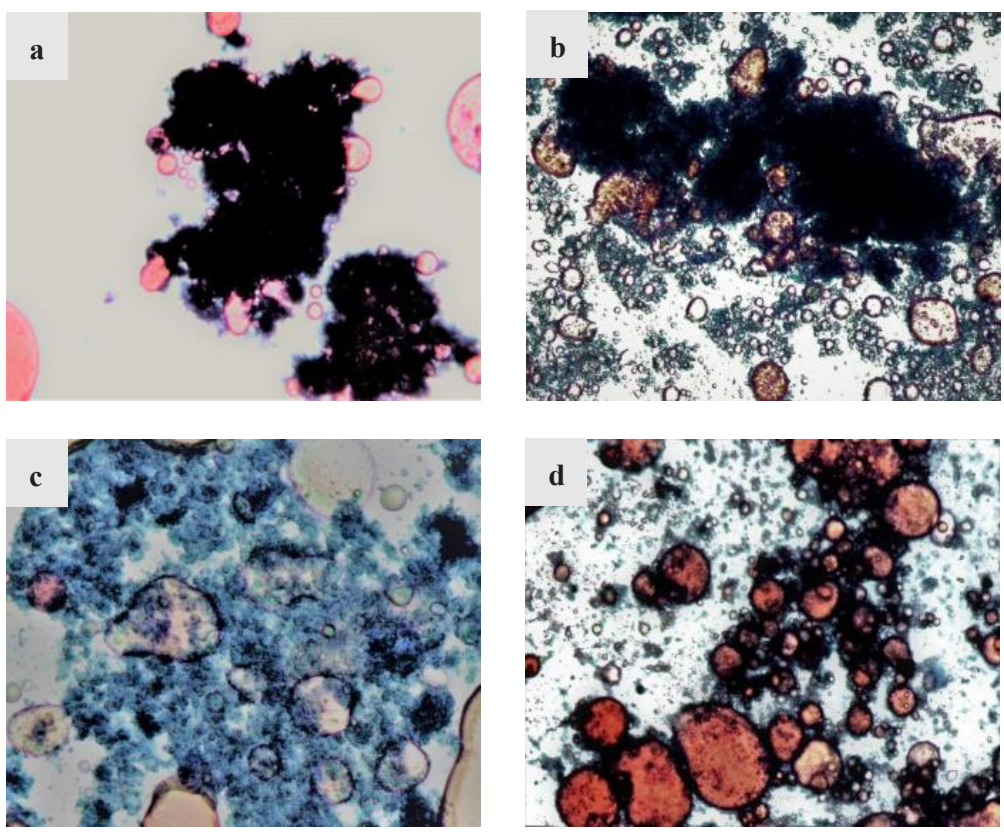

Fig. 2. Microstructure diagram of raw materials processed by different extraction methods. (a) raw material, (b) water extraction, (c) $\mathrm{KOH}$ hydrolysis, (d) neutral protease hydrolysis (all figures were observed in 200x).

effect of protein molecules was still obvious, resulting in a low fish oil extraction rate. In Fig. 2c, the hydrolysis of $\mathrm{KOH}$ caused the loose structure of protein molecules, made it easier for lipid separation but caused lipid loss due to the alkaline reaction condition. As for enzymatic hydrolysis method by neutrase, Fig. $2 \mathrm{~d}$ showed that the large protein molecules are hydrolyzed into smaller molecules and hence the lipid molecules could be easily freed from the binding effect of protein molecules by centrifu- 
gation, improving the extraction rate of fish oil.

\section{Significant influence of single-factor to the extraction rate}

The single-factor influence to fish oil extraction by neutrase were shown in Fig. 3 by one-way ANOVA analysis. Of all factors significant to the fish oil extraction, liquid-solid ratio, $\mathrm{pH}$ and extraction time displayed $p$-value less than 0.001 while the $p$-value of extraction time was 0.001 .

The influence of liquid-solid ratio was shown in Fig. 3a with the highest extraction rate reached was $54.18 \pm 1.47 \%$ under the liquid-solid ratio in 2:1. With the increase of liquid-solid ratio, the extraction rate of fish oil increased initially

a

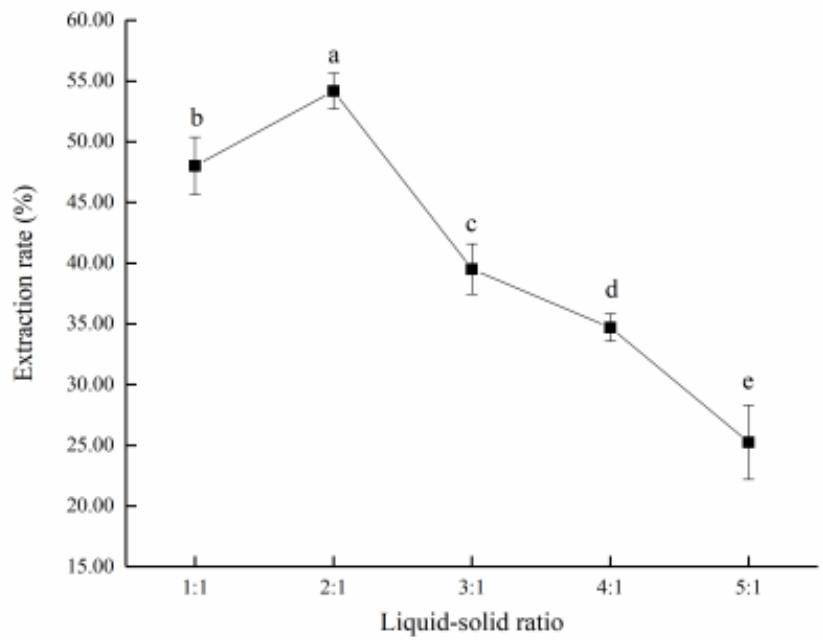

C

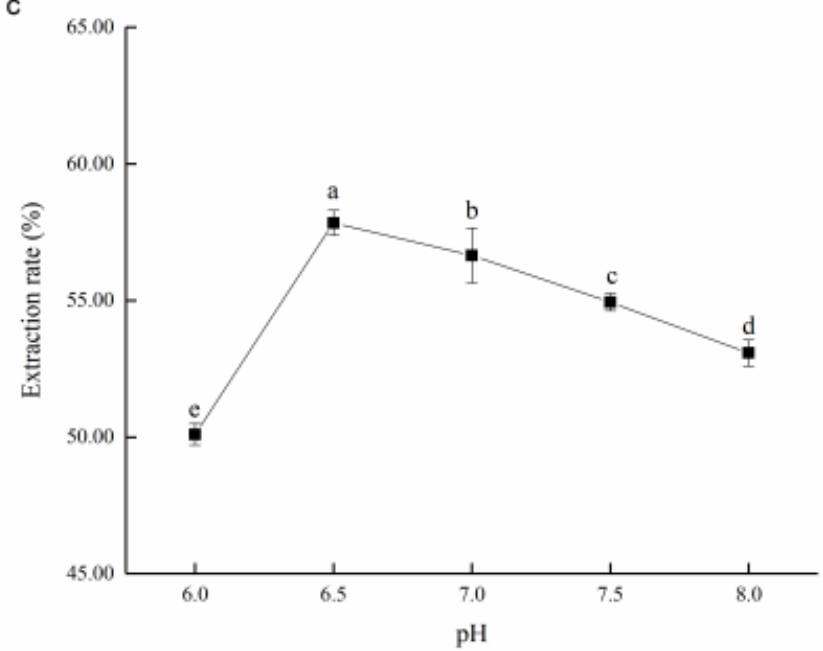

before decreasing. At low liquid-solid ratio was, a high concentration of substrate caused poor contact between enzyme and substrate, leading to an inefficient reaction. As the liquid-solid ratio increases, the substrate concentration gradually decreased, improving its fluidity in the reaction phase, and made it easier to react with enzyme. Further increase in the liquid-solid ratio beyond the optimal point would significantly decrease the concentration of substrate and enzyme, resulting in the decrease of extraction rate (Wang et al., 2020). Furthermore, the increase of water in the reaction may promote the formation of emulsifying layer, causing the absorption of lipid and subsequent decrease of extraction rate (Aitta et al., 2021). Thus, the best liquid-solid

b

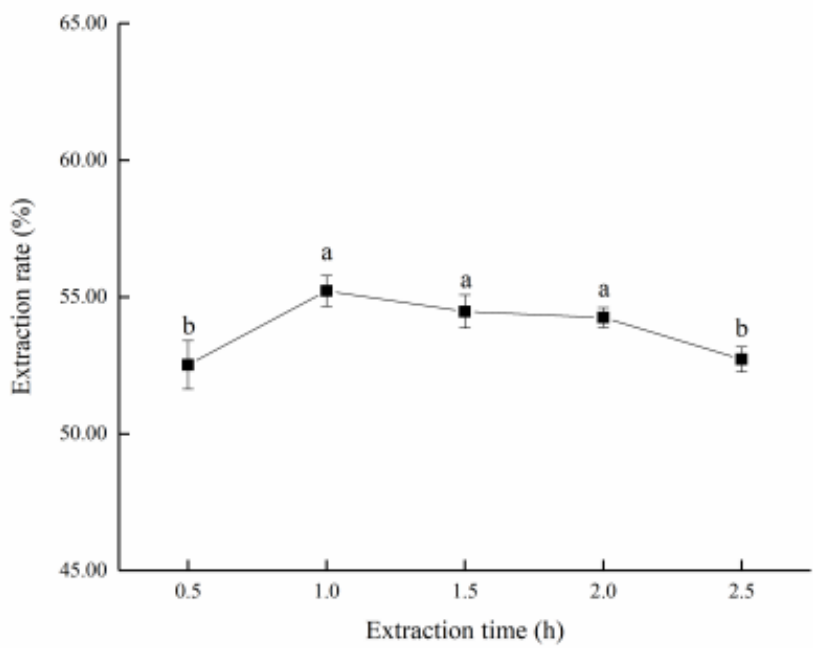

d

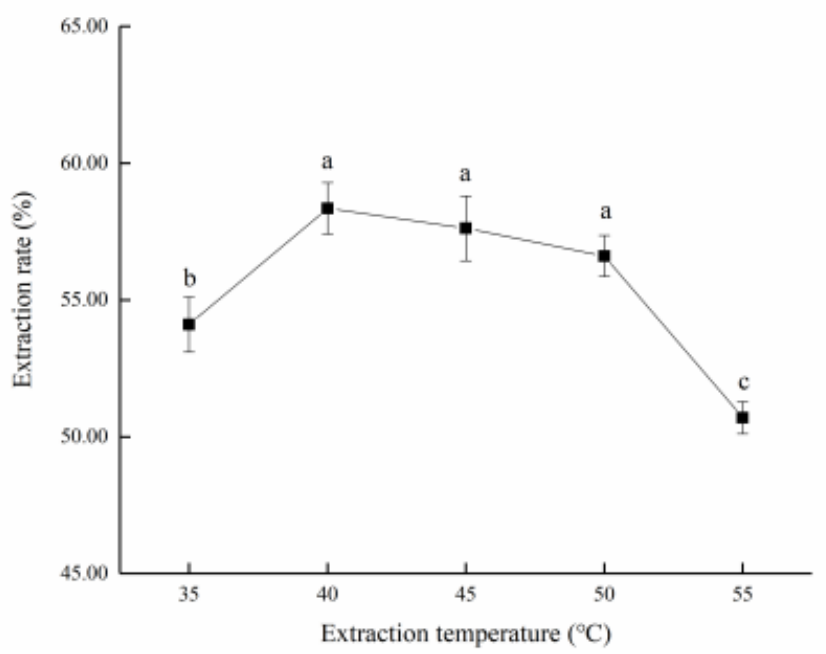

Fig. 3. Effect of one-factor on the fish oil extraction rate. (a) liquid-solid rate, (b) extraction time, (c) pH, (d) extraction temperature. Means with different superscript represents significantly differ $(p<0.05)$. 
ratio was around 2:1.

As for extraction time, it could be seen from Fig. $3 b$ that when the extraction time was short, there was insufficient reaction time between enzyme and substrate, leading to a low extraction rate. With the extension in extraction time, the extraction rate of fish oil gradually increased until a maximal was reached at $1.0 \mathrm{~h}(55.22 \pm 0.56 \%)$. Further extension in extraction time would see the oxidation and hydrolysis of a large amount of UFA in fish oil, resulting in a decrease in the extraction rate and quality of fish oil (Fang et al., 2016). The extraction rate of fish oil had little difference after $1.0 \mathrm{~h}$ and hence the extraction time in subsequent experiments was set at $1.0 \mathrm{~h}$.

The influence of $\mathrm{pH}$ was shown in Fig. $3 \mathrm{c}$ results indicated that the best $\mathrm{pH}$ of reaction was about 6.5 resulting in a extraction rate of $57.84 \pm 0.46 \%$. The extraction rate was generally higher in neutral range, and decreased with reaction shifted to alkaline. Different enzymes had their own optimal reaction $\mathrm{pH}$, where the dissociation groups of enzyme and substrate could stay in a specific dissociation state. In this state, the enzyme and the substrate could rapidly come into contact and react (Blum et al., 2018). Therefore, the optimal $\mathrm{pH}$ of fish oil extraction for neutrase was determined as 6.5 .

The single-factor experiments also verified the best extraction temperature as under $40{ }^{\circ} \mathrm{C}$ with the extraction rate reaching $58.35 \pm 0.94 \%$. The results in Fig. $3 d$ revealed that with the increase of temperature, the extraction rate of fish oil first increased and then decreased, reaching the maximum value at about $40^{\circ} \mathrm{C}$. It is known that temperature changes would affect enzyme activity and reaction rate. In the early stages, , the improvement of reaction rate with the rise of temperature played a dominant role resulting in an overall increase in the extraction rate. However, as the temperature further increases, the enzyme inactivation starts to occur, and the effect of thermal inactivation on the enzymes would be more significant than the effect of increased reaction rate, leading to a decrease in overall extraction rate (de Oliveira et al., 2016). In addition, as UFA are unstable at high temperature, an inappropriate temperature may lead to the oxidative decomposition of fish oil. Therefore, in subsequent experiments, the extraction temperature was set at $40^{\circ} \mathrm{C}$.

The single-factor experiments explained the significant effects of several independent factors on fish oil extraction rate, and the results identified the optimal parameters as liquid-solid ratio of 2:1, $1.0 \mathrm{~h}$ of extraction time in, $\mathrm{pH} 6.5$ and temperature at $40^{\circ} \mathrm{C}$.

\section{Response surface analysis with extremely significance and good regression effect}

The former results from single-factor experiment had indicated a relative satisfied extraction condition for fish oil. However, a further optimization to the extraction condition is also necessary for a higher extraction rate and material recovery. The RSM is a common way for process optimization, it can determine the effect of single-factors to testing index, verify the interaction between factors and establish an optimal process condition, providing more information of reference value with less time consuming (Luo, 2012). Following the results from single-factor experiment, the factors which had significant influence to the extraction rate were served as variables in response surface analysis. The liquid-solid ratio (A), extraction temperature (B) and $\mathrm{pH}(\mathrm{C})$ were chosen as variables with the fish oil extraction rate set as the response value $\mathrm{Y}$ (extraction time of $1.0 \mathrm{~h}$, enzyme concentration at 2,000 IU/g).

\section{Verification of the significance of response surface model and variables to response value}

The optimization design of experiment and related statistics were shown in Table 3 where the maximum extraction rate was shown to reach about 58\%. Multiple regression analysis was performed by Design-Expert 8.0 and a polynomial equation was calculated by setting the fish oil extraction rate as the independent variable. The polynomial equation was shown as follow:

$$
\begin{aligned}
\mathrm{Y}= & -707.06025+62.017 \mathrm{~A}+8.6259 \mathrm{~B}+162.304 \mathrm{C}- \\
& 0.025 \mathrm{AB}-1.75 \mathrm{AC}+0.179 \mathrm{BC}-12.723 \mathrm{~A}^{2}-0.12043 \mathrm{~B}^{2} \\
& -12.703 \mathrm{C}^{2}
\end{aligned}
$$

The results in Table 4 revealed that the determination coefficient $\left(R^{2}\right)$ of the model was 0.9947 and the $p$-value (prob $>F$ ) of model was extremely low $(<0.0001)$, indicated a good fit of the derived model. The $F$-value related to the lack of fit was not significant $(>0.05)$, which strengthen the validity of the model. Furthermore, the coefficient of variation was 0.62 , indicating high precision and accuracy of the experimental results (Wenwei et al., 2019). In addition, the predictability of the model and the significant influence of each experimental factor to response value were also verified (Zhang et al., 2012). It could be seen that the variable with the most significant effect to extraction rate was liquid-solid rate (A) compared to the effects of other variables $(B$ and $C)$ were also significant $(p<0.05)$. The inter- 
action coefficients included $\mathrm{AC}$ and $\mathrm{BC}$ were also significant when $p$-value $<0.05$. The quadratic coefficients $\left(\mathrm{A}^{2}, \mathrm{~B}^{2}\right.$, and $\left.\mathrm{C}^{2}\right)$ were all extremely significant when the $p$-value was less than 0.0001 . These results revealed the obvious significance of response surface model and the significant effects of variables to

Table 3. RSM experimental design and results analysis

\begin{tabular}{lllll}
\hline Group & A & B & C & Extraction rate (\%) \\
\hline 1 & -1 & 1 & 0 & $53.71 \pm 1.40$ \\
2 & -1 & 0 & 1 & $53.59 \pm 2.78$ \\
3 & -1 & 0 & -1 & $51.55 \pm 2.42$ \\
4 & 1 & 0 & -1 & $51.56 \pm 0.28$ \\
5 & 0 & -1 & -1 & $51.99 \pm 1.28$ \\
6 & -1 & -1 & 0 & $52.53 \pm 0.98$ \\
7 & 1 & 0 & 1 & $51.85 \pm 0.74$ \\
8 & 0 & 1 & -1 & $52.14 \pm 0.54$ \\
9 & 1 & -1 & 0 & $51.02 \pm 0.18$ \\
10 & 0 & 0 & 0 & $58.76 \pm 0.70$ \\
11 & 0 & 0 & 0 & $58.29 \pm 2.15$ \\
12 & 1 & 1 & 0 & $51.95 \pm 0.79$ \\
13 & 1 & 0 & 0 & $58.53 \pm 1.66$ \\
14 & 1 & 1 & 1 & $53.52 \pm 0.24$ \\
15 & 0 & -1 & 1 & $51.58 \pm 1.40$ \\
16 & 0 & 0 & 0 & $58.19 \pm 0.84$ \\
17 & 0 & 0 & 0 & $58.70 \pm 0.69$ \\
\hline
\end{tabular}

RSM, response surface methodology. the response value $(\mathrm{Y})$.

Interaction verification between variables by response surface plots and contour plots

Response surface plots and contour plots are more intuitive ways to express the interaction between independent variables in the regression model and the effects to response value. A contour plot that trended to an elliptical curve indicated a more significant interaction between the independent variables (Guo et al., 2010). As shown in Fig. 4, the response surface plots indicated that any two variables could affect the extraction rate as demonstrated by the quadratic effects. For contour plots, the circular contour plot shown in Fig. 4a revealed that the interaction between liquid-solid ratio and extraction temperature was not significant to the extraction rate with the result was similar with the $p$-value assessment $(p=0.7185$ ) by multiple regression analysis. The contour plots in Fig. $4 \mathrm{~b}$ and Fig. $4 \mathrm{c}$ showed an elliptical trend, which was due to the $\mathrm{pH}(\mathrm{C})$ having significant interaction with liquid-solid ratio (A) and extraction temperature (B), respectively.

\section{Extraction rate compare between optimum conditions and modified conditions}

According to the results from single-factor experiments and plots analysis in response surface, the best value obtained for each factor were liquid-solid ratio of 2:1, extraction temperature

Table 4. Analysis of variance for the fitted quadratic polynomial model

\begin{tabular}{|c|c|c|c|c|c|}
\hline Source & Sum of squares & Degree of freedom & Mean square & $F$-value & Prob $>F$ \\
\hline Model & 145.99 & 9 & 16.22 & 146.28 & $<0.0001$ \\
\hline Residual & 0.78 & 7 & 0.11 & & \\
\hline Lack of fit & 0.53 & 3 & 0.18 & 2.83 & $<0.0001$ \\
\hline Pure error & 0.25 & 4 & 0.062 & & 0.1703 \\
\hline A & 3.12 & 1 & 3.12 & 28.18 & 0.0011 \\
\hline B & 2.21 & 1 & 2.21 & 19.88 & 0.0029 \\
\hline C & 1.36 & 1 & 1.36 & 12.28 & 0.0099 \\
\hline$A B$ & 0.016 & 1 & 0.016 & 0.14 & 0.7185 \\
\hline$A C$ & 0.77 & 1 & 0.77 & 6.9 & 0.034 \\
\hline BC & 0.8 & 1 & 0.8 & 7.22 & 0.0312 \\
\hline$A^{2}$ & 42.6 & 1 & 42.6 & 384.16 & $<0.0001$ \\
\hline$B^{2}$ & 38.17 & 1 & 38.17 & 344.19 & $<0.0001$ \\
\hline$C^{2}$ & 42.46 & 1 & 42.46 & 382.95 & $<0.0001$ \\
\hline \multirow[t]{2}{*}{ Cor total } & 146.76 & 16 & & & \\
\hline & $R^{2}=0.9947$ & $R_{a d j}^{2}=0.9879$ & $C V=0.62$ & & \\
\hline
\end{tabular}



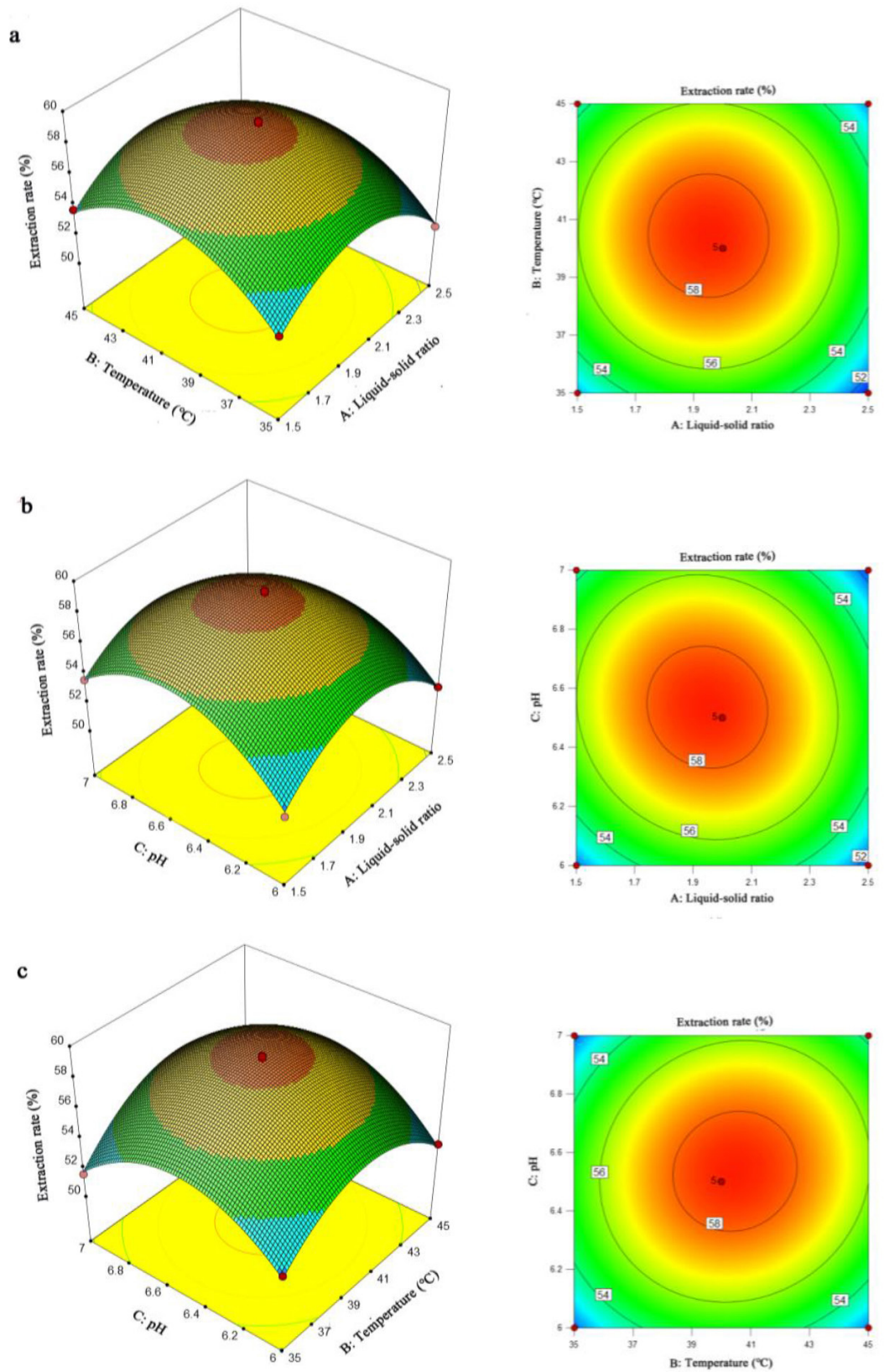

Fig. 4. Response surface plots and contour plots of extraction rate under factor interaction. (a) liquid-solid ratio and extraction temperature, (b) liquid-solid ratio and $\mathrm{pH},(\mathrm{c})$ extraction temperature and $\mathrm{pH}$.

at $40{ }^{\circ} \mathrm{C}$ and $\mathrm{pH}$ 6.5. The optimal extraction conditions analyzed by RSM is listed in Table 5 with the liquid-solid ratio being 1.95:1, extraction temperature at $40.47^{\circ} \mathrm{C}$ and $\mathrm{pH} 6.5$. The predicted extraction rate under optimum conditions was 58.56\%. With the temperature modified to a more practical value of $40.5^{\circ} \mathrm{C}$, the extraction rate achieved was $58.40 \pm 0.25 \%$, which was identical to the predicted value. These results suggest that
RSM could be used to optimize the extraction process. However, the optimized extraction rate was only about $60 \%$ when the loss of fish oil still took a large proportion. The loss of fish oil during extraction was a critical problem when the reaction environment and subsequent collection methods were important for a higher extraction rate. During the extraction process, considering the instability of fatty acids, a proper reaction en- 
Table 5. Extraction rate under optimum conditions and modified conditions

\begin{tabular}{lllll}
\hline Conditions & Liquid-solid ratio & Extraction temperature $\left({ }^{\circ} \mathrm{C}\right)$ & $\mathrm{pH}$ & Extraction rate $(\%)$ \\
\hline Optimum extraction conditions & $1.95: 1$ & 40.47 & 6.5 & $58.56 \%$ \\
Modified extraction conditions & $2.00: 1$ & 40.50 & 6.5 & $58.40 \pm 0.25 \%$ \\
\hline
\end{tabular}

vironment was essential when the pretreatment method of raw material, stirring rate of material-enzyme mixture, addition of antioxidants and control of vacuum degree, etc were valuable research points for a higher extraction rate (Let et al., 2005; Miyashita et al., 2018). Meanwhile, the subsequent separation of fish oil was also a critical point when the multiple centrifugal treatment and extra enzymatic treatment for centrifugal precipitation could potentially raise the extraction rate during separation process. Hence, the further extraction condition optimization in future study is essential and vital for a more satisfied fish oil extraction rate.

\section{A large proportion of unsaturated fatty acids in fish oil}

The fatty acids composition in fish oil obtained from the optimized extraction conditions was analyzed by GC-MS (Table 6) and the gas chromatogram was shown in Fig. 5. The length of fatty acids in Lophius litulon liver oil ranged from 12- to 26-carbon, with $19.75 \%$ being saturated fatty acids (SFA) and $80.25 \%$ UFA. The UFA contained $33.64 \%$ of monounsaturated fatty acids (MUFA) and $46.61 \%$ of PUFA. The content of DHA and EPA were $8.06 \%$ and $1.19 \%$, respectively. The ratio of DHA and EPA in Lophius litulon liver oil was about 6.77:1. Although the recommended intake ratio of DHA and EPA was not standardized around the world, some countries and organisms had set some suggestions with the consumes of EPA and DHA (Mozaffarian $\& \mathrm{Wu}, 2012$ ). The dietary Guidelines for Americans indicated the recommend diary intake of DHA plus EPA was about $250 \mathrm{mg}$ (Brault \& Miketinas, 2021). The recommendations proposed by WHO in 2010 suggested the pregnant and lactating women should daily intake $300 \mathrm{mg}$ DHA plus EPA with at least $200 \mathrm{mg}$ DHA containing (Ghasemi Fard et al., 2019). The European Food Safety Authority (EFSA) also suggested the 250 $\mathrm{mg}$ /day intake of DHA plus EPA for adults and the pregnant and lactating women were recommend additional 100-200 mg/ day intake of DHA. The EFSA also indicated the infants between 6 months and 24 months should intake $100 \mathrm{mg}$ DHA per day when the older children should intake the same DHA as the adult recommendation (Forsyth et al., 2016). And in recent years, the EFSA have made a clear regulation that the infant
Table 6. Fatty acid composition analysis of fish oil by GC-MS

\begin{tabular}{|c|c|c|c|}
\hline NO. & Retention time (min) & Fatty acid type & $\begin{array}{l}\text { Percentage } \\
\text { composition (\%) }\end{array}$ \\
\hline 1 & 12.82 & $\mathrm{C}_{12: 0}$ (lauric acid) & 0.03 \\
\hline 2 & 13.31 & $C_{13: 0}$ & 13.32 \\
\hline 3 & 13.68 & $\mathrm{C}_{14: 0}$ (myristic acid) & 2.43 \\
\hline 4 & 13.83 & $C_{14: 1}$ & 0.20 \\
\hline 5 & 14.89 & $C_{15: 0}$ & 0.12 \\
\hline 6 & 15.08 & $C_{15: 1}$ & 2.58 \\
\hline 7 & 16.25 & $C_{16: 1}$ & 9.79 \\
\hline 8 & 15.96 & $C_{16: 3}$ & 0.57 \\
\hline 9 & 24.05 & $C_{17: 0}$ & 3.37 \\
\hline 10 & 20.18 & $C_{17: 1}$ & 3.24 \\
\hline 11 & 20.04 & $\mathrm{C}_{18: 0}($ stearic acid $)$ & 0.28 \\
\hline 12 & 19.91 & $\mathrm{C}_{18: 1}$ (oleic acid) & 9.12 \\
\hline 13 & 19.70 & $\mathrm{C}_{18: 2}$ (linoleic acid) & 15.74 \\
\hline 14 & 19.28 & $\mathrm{C}_{18: 4}$ & 4.34 \\
\hline 15 & 29.65 & $C_{19: 0}$ & 0.13 \\
\hline 16 & 21.51 & $C_{19: 1}$ & 0.53 \\
\hline 17 & 23.80 & $C_{20: 1}$ & 1.48 \\
\hline 18 & 25.86 & $C_{20: 2}$ & 0.33 \\
\hline 19 & 27.58 & $C_{20: 3}$ & 1.28 \\
\hline 20 & 22.57 & $\mathrm{C}_{20: 4}$ (arachidonic acid) & 12.14 \\
\hline 21 & 23.11 & $\mathrm{C}_{20: 5}(\mathrm{EPA})$ & 1.19 \\
\hline 22 & 26.37 & $C_{21: 3}$ & 0.18 \\
\hline 23 & 25.62 & $C_{21: 5}$ & 0.16 \\
\hline 24 & 27.93 & $C_{22: 1}$ & 5.79 \\
\hline 25 & 27.40 & $C_{22: 4}$ & 2.21 \\
\hline 26 & 26.64 & $\mathrm{C}_{22: 5}(\mathrm{DPA})$ & 0.23 \\
\hline 27 & 26.88 & $\mathrm{C}_{22: 6}(\mathrm{DHA})$ & 8.06 \\
\hline 28 & 34.24 & $C_{24: 0}$ & 0.09 \\
\hline 29 & 32.73 & $C_{24: 1}$ & 0.86 \\
\hline 30 & 31.93 & $C_{24: 5}$ & 0.04 \\
\hline 31 & 31.67 & $C_{25: 6}$ & 0.14 \\
\hline
\end{tabular}

GC-MS, chromatograph-mass spectrometer; EPA, eicosapentaenoic acid; DPA:docosapentaenoic acid; DHA:adocosahexaenoic acid.

milk powder sold in the European Union should meet the additive standard when the content of DHA should achieve to 20$50 \mathrm{mg}$ per $100 \mathrm{kcal}$, which was equal to the proportion about 


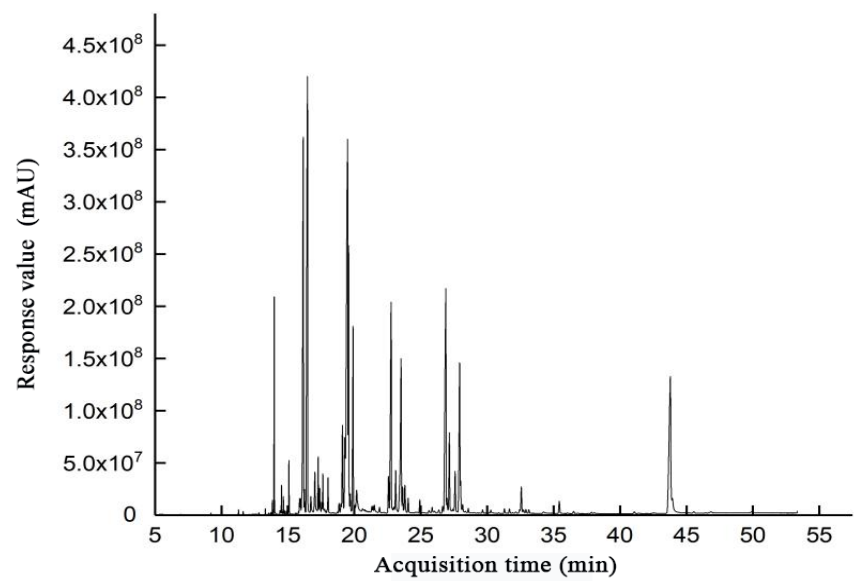

Fig. 5. Gas chromatogram of fatty acid composition in fish oil.

$0.5 \%-1.0 \%$ in fatty acids (Koletzko et al., 2020). The recent research suggested that the fish oil from tuna is of high quality when the ratio of DNA and EPA content is about 5:1, which was a good ratio for human intake (Zhang et al., 2020). The ratio of DHA and EPA in the fish oil gained in this study was higher than 5:1, indicating the fish oil extracted from Lophius litulon liver is of great value and has the potential application for the production of high- quality fish oil.

Meanwhile, the refining of fish oil was important for the improvement of fish oil quality (Menegazzo et al., 2014). The fish oil obtained from this study was unrefined with certain impurities and quality indexes to be optimized. In addition, the great amount of UFA could also be enriched and transported into more PUFA by some separation technology and the application of lipase. The application of enrichment technology such as low temperature crystallization, urea adduction, molecular distillation and super/subcritical fluid extraction, etc could enrich the fatty acids with more proportion of UFA (Rubio-Rodríguez et al., 2010; Xie et al., 2019). The application of some lipase could even raise the amount and proportion of PUFA by their selective hydrolysis and recombination effects to glycerides in fish oil (Castejón \& Señoráns, 2020). These optimization methods will raise the overall quality of fish oil with high content of UFA and satisfied proportion, and our future study will focus on these points for the quality improvement of fish oil extracted from Lophius litulon.

\section{Conclusion}

The Lophius litulon liver had a high content of lipid and we

compared multiple fish oil extraction methods using single-factor experiments. The best extraction method was determined to be neutrase hydrolysis and was further optimized via RSM using Box-Behnken design. The optimized extraction rate by neutrase hydrolysis could achieve a rate up to $58.40 \pm 0.25 \%$, with extracted fish oil containing high proportion of UFAs as analyzed by GC-MS. Moreover, the quality of the extracted fish oil was deemed good as the DHA/EPA ratio was $6.77: 1$, which was higher than the recommended ratio from recent researches (5:1). The results from this study revealed the potential added-value application of Lophius litulon liver for production of high-quality fish oil.

\section{Competing interests}

No potential conflict of interest relevant to this article was reported.

\section{Funding sources}

This work was financially supported by the National Natural Science Foundation of China (NSFC31871868), Hainan Provincial Natural Science Foundation of China (321CXTD1012) and Scientific Research Foundation of Hainan Tropical Ocean University (RHDRC202117).

\section{Acknowledgements}

Not applicable.

\section{Availability of data and materials}

Upon reasonable request, the datasets of this study can be available from the corresponding author.

\section{Ethics approval and consent to participate}

This article does not require IRB/IACUC approval because there are no human and animal participants.

\section{ORCID}

Zhiheng $\mathrm{Hu}$

Yaoxian Chin

Jialin Liu

Jiaying Zhou

Gaoshang Li

Lingping $\mathrm{Hu}$

Yaqin $\mathrm{Hu}$ https://orcid.org/0000-0002-8557-8666 https://orcid.org/0000-0001-9612-9295 https://orcid.org/0000-0002-2677-7024 https://orcid.org/0000-0002-9439-6397 https://orcid.org/0000-0002-2372-8243 https://orcid.org/0000-0001-8826-4526 https://orcid.org/0000-0002-8557-8666 


\section{References}

Adeoti IA, Hawboldt K. A review of lipid extraction from fish processing by-product for use as a biofuel. Biomass Bioenergy. 2014;63:330-40.

Aguilera-Oviedo J, Yara-Varón E, Torres M, Canela-Garayoa R, Balcells M. Sustainable synthesis of omega-3 fatty acid ethyl esters from monkfish liver oil. Catalysts. 2021;11:100.

Alfio VG, Manzo C, Micillo R. From fish waste to value: an overview of the sustainable recovery of omega-3 for food supplements. Molecules. 2021;26:1002.

Aitta E, Marsol-Vall A, Damerau A, Yang B. Enzyme-assisted extraction of fish oil from whole fish and by-products of baltic herring (Clupea harengus membras). Foods. 2021;10:1811.

Blum JM, Su Q, Ma Y, Valverde-Pérez B, Domingo-Félez C, Jensen $\mathrm{MM}$, et al. The $\mathrm{pH}$ dependency of $\mathrm{N}$-converting enzymatic processes, pathways and microbes: effect on net $\mathrm{N}_{2} \mathrm{O}$ production. Environ Microbiol. 2018;20:1623-40.

Brault H, Miketinas D. Adequate intake of docosahexaenoic acid for adults: NHANES 2015-2016 (P18-032-19). Curr Dev Nutr. 2019;3:nzz039.

Castejón N, Señoráns FJ. Enzymatic modification to produce health-promoting lipids from fish oil, algae and other new omega-3 sources: a review. N Biotechnol. 2020;57:45-54.

Dragalin I, Morarescu O, Sedcenco M, Rosca RM. GC-MS analysis of the fatty acids methyl esters in Japanese quail fat. Chem J Mold. 2015;10:54-7.

de Oliveira DASB, Minozzo MG, Licodiedoff S, Waszczynskyj N. Physicochemical and sensory characterization of refined and deodorized tuna (Thunnus albacares) by-product oil obtained by enzymatic hydrolysis. Food Chem. 2016;207:187-94.

Fang X, Fei X, Sun H, Jin Y. Aqueous enzymatic extraction and demulsification of camellia seed oil (Camellia oleifera Abel.) and the oil's physicochemical properties. Eur J Lipid Sci Technol. 2016;118:244-51.

Forsyth S, Gautier S, Salem N Jr. Global estimates of dietary intake of docosahexaenoic acid and arachidonic acid in developing and developed countries. Ann Nutr Metab. 2016;68:258-67.

Gulzar S, Raju N, Nagarajarao RC, Benjakul S. Oil and pigments from shrimp processing by-products: extraction, composition, bioactivities and its application- a review. Trends Food Sci Technol. 2020;100:307-19.
Guo X, Zou X, Sun M. Optimization of extraction process by response surface methodology and preliminary characterization of polysaccharides from Phellinus igniarius. Carbohydr Polym. 2010;80:344-9.

Ghasemi Fard S, Wang F, Sinclair AJ, Elliott G, Turchini GM. How does high DHA fish oil affect health? A systematic review of evidence. J Crit Rev Food Sci Nutr. 2019;59:1684727.

Haddar A, Fakhfakh-Zouari N, Hmidet N, Frikha F, Nasri M, Kamoun AS. Low-cost fermentation medium for alkaline protease production by Bacillus mojavensis A21 using hulled grain of wheat and sardinella peptone. J Biosci Bioeng. 2010;110:288-94.

Hathwar SC, Bijinu B, Rai AK, Narayan B. Simultaneous recovery of lipids and proteins by enzymatic hydrolysis of fish industry waste using different commercial proteases. Appl Biochem Biotechnol. 2011;164:115-24.

Han Z, Xu S, Sun J, Yue X, Wu Z, Shao JH, et al. Effects of fatty acid saturation degree on salt-soluble pork protein conformation and interfacial adsorption characteristics at the oil/ water interface. J. Food Hydrocoll. 2021;113:106472.

Jamshidi A, Cao H, Xiao J, Simal-Gandara J. Advantages of techniques to fortify food products with the benefits of fish oil. Food Res Int. 2020;137:109353.

Jensen CL, Maude M, Anderson RE, Heird WC. Effect of docosahexaenoic acid supplementation of lactating women on the fatty acid composition of breast milk lipids and maternal and infant plasma phospholipids. Am J Clin Nutr. 2000;71:S292-9.

Kaur N, Chugh V, Gupta AK. Essential fatty acids as functional components of foods: a review. J Food Sci Technol. 2014;51:2289-303.

Koletzko B, Bergmann K, Brenna JT, Calder PC, Campoy C, Clandinin MT, et al. Should formula for infants provide arachidonic acid along with DHA? A position paper of the European Academy of Paediatrics and the Child Health Foundation. Am J Clin Nutr. 2020;111:10-16.

Lunn J, Theobald HE. The health effects of dietary unsaturated fatty acids. Nutr Bull. 2006;31:178-224.

Laurenson $\mathrm{CH}$, Priede IG. The diet and trophic ecology of anglerfish Lophius piscatorius at the Shetland islands, UK. J Mar Biol Assoc UK. 2005;85:419-24.

Lin N, Mo X, Yang Y, Zhang H. Purification and sequence characterization of chondroitin sulfate and dermatan sulfate from fishes. Glycoconj J. 2017;34:241-53. 
Loftsson T, Ilievska B, Asgrimsdottir GM, Ormarsson OT, Stefansson E. Fatty acids from marine lipids: biological activity, formulation and stability. J Drug Deliv Sci Technol. 2016;34:71-5.

Luque de Castro MD, Priego-Capote F. Soxhlet extraction: past and present panacea. J Chromatogr A. 2010;1217:2383-9.

Luo D. Optimization of total polysaccharide extraction from Dioscorea nipponica Makino using response surface methodology and uniform design. Carbohydr Polym. 2012;90:284-8.

Let MB, Jacobsen C, Pham KA, Meyer AS. Protection against oxidation of fish-oil-enriched milk emulsions through addition of rapeseed oil or antioxidants. J Agric Food Chem. 2005;53:5429-37.

Maqsood S, Benjakul S, Kamal-Eldin A. Extraction, processing, and stabilization of health-promoting fish oils. Recent Pat Food Nutr Agric. 2012;4:141-7.

Marsol-Vall A, Aitta E, Guo Z, Yang B. Green technologies for production of oils rich in $n$-3 polyunsaturated fatty acids from aquatic sources. Crit Rev Food Sci Nutr. 2021:1-21.

Miyashita K, Uemura M, Hosokawa M. Effective prevention of oxidative deterioration of fish oil: focus on flavor deterioration. Annu Rev Food Sci Technol. 2018;9:209-26.

Mozaffarian D, Wu JHY. (n-3) fatty acids and cardiovascular health: are effects of EPA and DHA shared or complementary? J Nutr. 2012;142:614S-25S.

Menegazzo ML, Petenuci ME, Fonseca GG. Production and characterization of crude and refined oils obtained from the co-products of Nile tilapia and hybrid sorubim processing. Food Chem. 2014;157:100-4.

Qi-yuan L, Jun-qing Q, Xiao-ge W. Optimization of enzymatic fish oil extraction from mackerel viscera by response surface methodology. Int Food Res J. 2016;23:992-7.

Rebah FB, Miled N. Fish processing wastes for microbial enzyme production: a review. 3 Biotech. 2013;3:255-65.

Rubio-Rodríguez N, Beltrán S, Jaime I, de Diego SM, Sanz MT, Carballido JR. Production of omega-3 polyunsaturated fatty acid concentrates: a review. Innov Food Sci Emerg Technol. 2010;11:1-12.

Sargent J, Bell G, McEvoy L, Tocher D, Estevez A. Recent developments in the essential fatty acid nutrition of fish. Aquaculture. 1999;177:191-9.

Stollewerk K, Jofré A, Comaposada J, Arnau J, Garriga M. Food safety and microbiological quality aspects of QDS process ${ }^{\circledR}$ and high pressure treatment of fermented fish sausages.
Food Control. 2014;38:130-5.

Swart J, Bordoloi A, Goosen NJ. Optimization of phosphate recovery from monkfish, Lophius vomerinus, processing by-products and characterization of the phosphate phases. J Sci Food Agric. 2019;99:2743-56.

Sahena F, Zaidul ISM, Jinap S, Saari N, Jahurul HA, Abbas KA, et al. PUFAs in fish: extraction, fractionation, importance in health. Compr Rev Food Sci Food Saf. 2009;8:59-74.

Shao JH, Deng YM, Zhou GH, Xu XL, Liu DY. A Raman spectroscopic study of meat protein/lipid interactions at protein/oil or protein/fat interfaces. Int J Food Sci Technol. 2015;50:982-9.

Vázquez JA, Menduíña A, Nogueira M, Durán AI, Sanz N, Valcarcel J, et al. Optimal production of protein hydrolysates from monkfish by-products: chemical features and associated biological activities. Molecules. 2020;25:4068.

Wang YH, Kuo CH, Lee CL, Kuo WC, Tsai ML, Sun PP, et al. Enzyme-assisted aqueous extraction of cobia liver oil and protein hydrolysates with antioxidant activity. Catalysts. 2020;10:1323.

Wenwei C, Guangrong H, Zhenbao J, Yao H. Optimization of aqueous enzymatic extraction of oil from shrimp processing by-products using response surface methodology. Food Sci Technol. 2019;39:231-6.

$\mathrm{Xu}$ J, Li Y, Regenstein J, Su X. In vitro and in vivo anti-oxidation and anti-fatigue effect of monkfish liver hydrolysate. Food Biosci. 2017;18:9-14.

Xie D, Gong M, Wei W, Jin J, Wang X, Wang X, et al. Antarctic krill (Euphausia superba) oil: a comprehensive review of chemical composition, extraction technologies, health benefits, and current applications. Compr Rev Food Sci Food Saf. 2019;18:514-34.

Yang ZH, Amar M, Sampson M, Courville AB, Sorokin AV, Gordon SM, et al. Comparison of omega-3 eicosapentaenoic acid versus docosahexaenoic acid-rich fish oil supplementation on plasma lipids and lipoproteins in normolipidemic adults. Nutrients. 2020;12:749.

Ying Y, Xiang Y, Liu J, Chen X, Hu L, Li Y, et al. Optimization of ultrasonic-assisted freezing of Penaeus chinensis by response surface methodology. Food Qual Saf. 2021;5:fyaa034.

Zhu Y, Yu J, Jiao C, Tong J, Zhang L. Optimization of quercetin extraction method in Dendrobium officinale by response surface methodology. Heliyon. 2019;5:e02374.

Zhang J, Cui C, Chen H, Liu J. The completion of esterification 
of free fatty acids in Zanthoxylum bungeanum seed oil with ethanol. Int J Green Energy. 2014;11:822-32.

Zhu BW, Qin L, Zhou DY, Wu HT, Wu J, Yang JF, et al. Extraction of lipid from sea urchin (Strongylocentrotus nudus) gonad by enzyme-assisted aqueous and supercritical carbon dioxide methods. Eur Food Res Technol. 2010;230:737-43.

Zhang Y, Li S, Yin C, Jiang D, Yan F, Xu T, et al. Response surface optimisation of aqueous enzymatic oil extraction from bayberry (Myrica rubra) kernels. Food Chem. 2012;135:304-8.

Zhang J, Yi C, Han J, Ming T, Zhou J, Lu C, et al. Novel high-docosahexaenoic-acid tuna oil supplementation modulates gut microbiota and alleviates obesity in high-fat diet mice. Food Sci Nutr. 2020;8:6513-27. 